\title{
Amelotin-Mediated Crystals Assembly in Liquid-Phase and on Tooth Surface
}

\author{
Xiaohua Ren, Min Zhou, Yandong Mu, Kun Tian* \\ School of Medicine, University of Electronic Science and Technology of China, Chengdu, China \\ Email: *tiankun78@hotmail.com
}

How to cite this paper: Ren, X.H., Zhou, M., Mu, Y.D. and Tian, K. (2021) Amelotin-Mediated Crystals Assembly in Liquid-Phase and on Tooth Surface. Journal of Materials Science and Chemical Engineering, 9, 35-44.

https://doi.org/10.4236/msce.2021.97004

Received: July 8, 2021

Accepted: July 27, 2021

Published: July 30, 2021

\begin{abstract}
Objectives: To study the role of amelotin in enamel formation, purified recombinant human amelotin was used in a study of amelotin self assembly and its role in new HAP crstal structure formation in a laboratory setting. Methods: The full-length human amelotin gene was cloned from developing tooth buds and recombinant amelotin was expressed and purified. Morphological changes during amelotin self-assembly and the role of amelotin in promoting new minieralization structure is studied using Transmission electronic microscopy and Scanning electron microscopy. Results: The measured molecular weight of expressed human amelotin was $28 \mathrm{kDa}$ that matches the predicted values. Amelotin self-assembles to form nano-spheres $10-30 \mathrm{~nm}$ in size. The amelotin self-assembly process further produces higher 3-D structure in the forms of chain-like fabric arranged in parallel and perpendicular direction. The neonatal pearl crystals were arranged side by side to form a string of small rods and small parallel rods extend from the demineralized glaze on the surface of teeth that were pre-treated with amelotin.
\end{abstract}

\section{Keywords}

Amelotin, Hydroxyapatite, Enamel, Mineralization, Electronic Microscopy

\section{Introduction}

The primary unit of tooth enamel is tightly packed hydroxyapatite (HAP) nanocrystals with a rough cross section of $33-65 \mathrm{~nm}$ and a c-axis length of 100 $1000 \mathrm{~nm}$ [1] [2]. The formation of dental enamel is initiated enamel organ and dental papilla [3]. The ameloblasts then secreted extracellular matrix proteins (EMPs), which play a major role in the following biomineralization $\mathrm{p} \mathrm{[4].} \mathrm{Three}$ main structural proteins in the EMPs are amelogenin (AMEL) enamelin (ENAM) and amphiphilic ameloblastin (AMBN) [5]. As indicated in loss-of-function ani- 
mal studies, the absence of these three proteins leads to enamel phenotype or even absence of enamel [6] [7] [8]. In this study, we subcloned the human recombinant AMTN gene and analyzed the crystal morphology and mineral phase of the surface of the nanocomposite in the presence of the recombinant human full-length AMTN using field emission scanning electron microscopy (FE-SEM) and X-ray Diffraction (XRD).

\section{Materials and Methods}

\subsection{DNA Constructs}

Tooth germs of impacted human mandibular third molars were extracted from children receiving orthodontic treatment in Sichuan Provincial People's Hospital. The study was approved by the Ethics Committee on Human Research of Sichuan Provincial People's Hospital (NO.20110308, OCT. 19th, 2011). Total RNA was then isolated from the soft tissues obtained from these tooth germs using TRIzol reagent (Invitrogen, Carlsbad, CA) and first strand cDNA was prepared using the HiFiScript cDNA Synthesis Kit (CWbiotech, Beijing, China). The following primers, designed according to the published human AMTN gene sequence (PubMed ID: 401138), were synthesized by Sangon Biotech (Shanghai, China): AMTN-EcoRI

(5'-TGGGTCGCGGATCCGAATTCATGAGGAGTACGATTCTACTG-3') and AMTN-SalI

(5'-GCGGCCGCAAGCTTGTCGACTTACTGAATTCCATTTGCTG-3'). The resulted PCR fragment was gel-purified and subcloned into the EcoRI-SalI site of the pMD18-T vector (TAKARA, Dalian, China). The newly constructed plasmid, pMD18-T-AMTN, was sequenced to confirm correct DNA sequence and orientation. The full-length hAMTN DNA fragment was then released from pMD18-T-AMTN by double digestion with EcoRI/Sall and ligated into the pET-28a (+) vector (Novagen, Madison, USA) which carries an $\mathrm{N}$-terminal His Tag $^{\oplus}$ configuration an optional C-terminal His $\bullet$ Tag sequence. The resulted new plasmid was named as pET-28a (+)-AMTN. The study was performed in accordance with the guidelines established by international ethics committees and was approved by the Medical Ethics Committee in Sichuan Provincial People's Hospital.

\subsection{Expression Optimization of Recombinant Full-Length hAMTN Protein}

After sequenced to confirm the correct cDNA insertion, pET-28a (+)-AMTN was transformed into the competent E. coli strains BL21 (DE3) or RossetaTM (Novagen, Madison, USA) using the heat-shock method. The clones containing hAMTN gene were selected by colony PCR. The expression of hAMTN protein was then induced by isopropythio- $\beta$-D-galactoside (IPTG) (Fluka, Buchs, Switzerland), with the concentration of IPTG, the cell density, the incubation time and temperature optimized to promote soluble hAMTN expression. The E. coli 
cultures were collected and centrifuged at $5000 \mathrm{rpm}$ for $2 \mathrm{~min}$. The cells were resuspended with $1 \mathrm{~mL}$ of phosphate buffered saline (PBS), sonicated in an ice bath for $10 \mathrm{~min}$, and centrifuged at $10,000 \mathrm{rpm}$ for $10 \mathrm{~min}$ at $4^{\circ} \mathrm{C}$. SDS-PAGE followed by Coomassie brilliant blue (CBB) staining was used to evaluate the protein level of hAMTN.3. Large-scale expression of hAMTN was achieved using the conditions optimized for soluble hAMTN expression. After incubation, E. coli cells were harvested by centrifugation at $5000 \mathrm{rpm}$ for $20 \mathrm{~min}$ at $4^{\circ} \mathrm{C}$. The cells were resuspended thoroughly in $40-\mathrm{mL}$ binding buffer $(500 \mathrm{mM} \mathrm{NaCl}, 25$ $\mathrm{mM}$ Tris- $\mathrm{HCl}, 20 \mathrm{mM}$ imidazole, $\mathrm{pH} 8.0$ ), sonicated in an ice bath for $30 \mathrm{~min}$, and centrifuged at $12,000 \mathrm{rpm}$ for $30 \mathrm{~min}$ at $4^{\circ} \mathrm{C}$. The supernatant was collected and stored at $4^{\circ} \mathrm{C}$. The hAMTN protein was then purified using a Ni-NTA Superflow Cartridge. Briefly, supernatants containing soluble hAMTN protein were incubated using a pre-equilibrated Ni-NTA column (GE Healthcare, Piscataway, USA) for $30 \mathrm{~min}$. The column was washed with the binding buffer, and the hAMTN protein was eluted by elution buffers containing a linear gradient of imidazole ranging from $50 \mathrm{mM}$ to $300 \mathrm{mM}$. The eluted protein was then centrifuged at $3600 \mathrm{rpm}$ for $30 \mathrm{~min}$ at $4^{\circ} \mathrm{C}$, filtered with a $0.22 \mu \mathrm{m}$ hollow fiber membrane, and loaded onto an anion-exchange Resource $\mathrm{Q}$ packed column (GE Healthcare, Piscataway, USA) which was pre-equilibrated with Buffer A (50 mM $\mathrm{NaCl}, 25 \mathrm{mM}$ Tris- $\mathrm{HCl} \mathrm{pH}$ 8.0). The column was then washed with Buffer A, and the hAMTN protein was eluted with a linear gradient of $100 \%$ buffer $A$ to $100 \%$ buffer B ( $1 \mathrm{M} \mathrm{NaCl}, 25 \mathrm{mM}$ Tris- $\mathrm{HCl} \mathrm{pH} \mathrm{8.0).} \mathrm{The} \mathrm{purified} \mathrm{hAMTN} \mathrm{pro-}$ tein was lyophilized using a freeze dryer and stored at $-80^{\circ} \mathrm{C}$.

\subsection{Western Blot}

The hAMTN protein sample was added to the SDS-PAGE loading buffer, and SDS-PAGE was performed. After gel electrophoresis, the protein was transferred from the gel onto a polyvinylidene fluoride (PVDF) membrane. The PVDF membrane was then blocked with nonfat milk, and probed with Mouse Anti-His Tag Monoclonal Antibody (GenScript, Piscataway, USA) followed by incubation with horseradish peroxidase (HRP)-conjugated Goat-Anti-Mouse IgG Secondary Antibody (GenScript, Piscataway, USA). Blots were visualized with enhanced chemiluminescent (ECL) reagents (Pierce Biotechnology, Rockford, USA).

\subsection{Self-Assembly of Full-Length Human AMTN Protein and Transmission Electronic Microscopy (TEM)}

AMTN stock solutions $(2 \mathrm{mg} / \mathrm{mL})$ were made by dissolving lyophilized AMTN protein in ice-cold distilled deionized water with the $\mathrm{pH}$ adjusted to 3.5. The stock solutions were stored at $4^{\circ} \mathrm{C}$ for at least $24 \mathrm{~h}$ to ensure complete dissolution. Reaction solutions of the AMTN protein $(100 \mu \mathrm{g} / \mathrm{mL}, \mathrm{pH}=7.6)$ were then prepared on ice by diluting the AMTN stock solutions with $50 \mathrm{mM}$ Tris- $\mathrm{HCl}$ $(\mathrm{pH}=7.6)$. All buffer solutions and water were filtered using a $0.22 \mu \mathrm{m}$ membrane filter. Sample aliquots $(10 \mu \mathrm{l})$ of the reaction AMTN solution were pipet- 
ted onto carbon coated Cu-grids (Electronic microscopy Sciences, Hatfield, PA) and incubated at room temperature for $1 \mathrm{~min}$ or $10 \mathrm{~min}$. The $\mathrm{Cu}$-grids were then blotted on filter paper, negatively stained with $1 \%$ filtered phospho-tungstic acid $(\mathrm{pH}=7.6)$ for $30 \mathrm{~s}$, blotted again and air-dried.TEM analysis was performed using a JEOL 2100 TEM microscope at $100 \mathrm{kV}$, in bright field. Images were captured using an AMT CCD camera (AMT, Danvers, USA). Image analyses (i.e., particle size measurements) were subsequently performed using ImageJ 1.64 (NIH, Bethesda, MD, http://rsb.info.nih.gov/ij/download.html).

\subsection{Preparation and Remineralization of Human Tooth Slices}

Tooth slices, $1 \mathrm{~mm}$ in thickness and $8-10 \mathrm{mM}$ in diameter, were prepared perpendicular to the long axis of the teeth from freshly extracted, caries-free human third molars with a low-speed hard tissue diamond saw (Allied High Tech Products, Rancho Dominguez, USA). After sonicated sequentially for $10 \mathrm{~min}$ each in detergents, acetone, $100 \%$ ethanol and distilled deionized water, the samples were etched with $30 \%$ phosphoric acid for $60 \mathrm{~s}$, washed thoroughly with distilled deionized water, and dried with a vacuum dryer. The tooth slices were then incubated with $1 \mathrm{~mL}$ of the AMTN reaction solutions at room temperature for $30 \mathrm{~min}$, and treated with $10 \mathrm{~mL}$ freshly prepared mineralization solutions at $37^{\circ} \mathrm{C}$ for 1 day, 3 days, and 7 days. The mineralization solution, with a $\mathrm{Ca}^{2+} / \mathrm{PO}_{4}^{3-}$ ratio of 1.67 , contained $3.0 \mathrm{mM} \mathrm{CaCl}_{2}, 1.5 \mathrm{mM} \mathrm{KH}_{2} \mathrm{PO}_{4}, 50 \mathrm{mM}$ Tris- $\mathrm{HCl}(\mathrm{pH}=7.6)$, and $180 \mathrm{mM} \mathrm{NaCl}$. The mineralization solutions were changed every 24 hours. Tooth slices only treated with the mineralization solutions served as controls. After the remineralization, tooth slices were washed with distilled deionized water and dried at room temperature.

\subsection{Scanning Electronic Microscopy (SEM) and X-Ray Diffraction Analysis (XRD)}

Surface morphology changes of the tooth slices were detected with a Phenom Desktop Scanning Electron Microscope (Phenom-World B.V., Eindhoven, Netherlands). The structure of newly formed crystals on the tooth slices was evaluated with XRD on a D/MAX-3A X-ray diffractometer (Rigaku, Japan) with $\mathrm{CuKa}$ radiation $(70 \mathrm{kV}$ and $50 \mathrm{~mA})$. The data was obtained in the range of diffraction angle $2 \theta=4^{\circ}-80^{\circ}$ with a step of $0.01^{\circ}$ and a scan rate of $0.01 \% \mathrm{~min}$.

\section{Results}

\subsection{Generation of Constructs Encoding Human AMTN Gene}

The full length human AMTN gene was successfully amplified, gel purified and subcloned into the EcoRI-SalI site of the pET-28a (+) vector (Figure 1(A)). The new plasmid was named as pET-28a (+)-AMTN. Correct DNA sequence and orientation of the hAMTN gene in pET-28a (+)-AMTN was confirmed (Figure $1(B))$. 

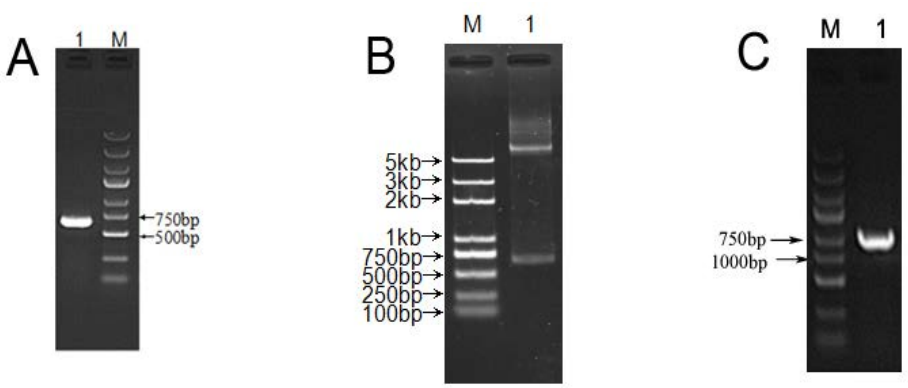

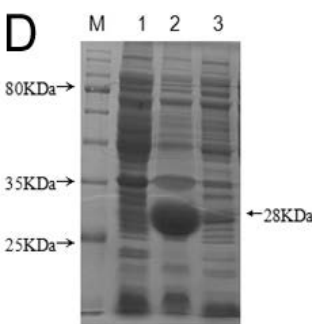

G

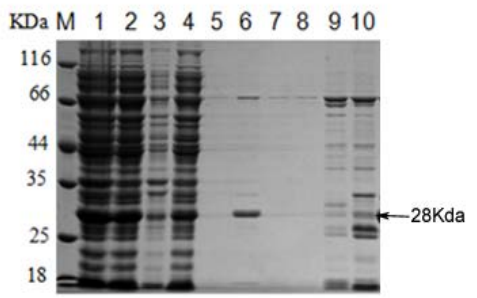

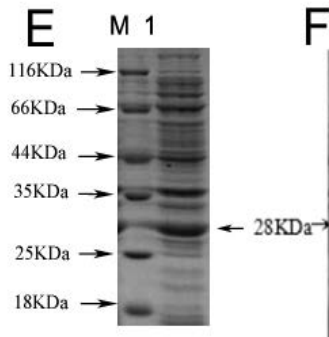

$\mathrm{H}$

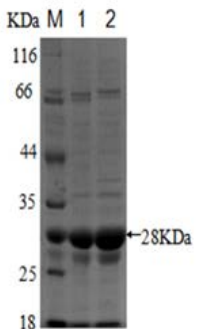

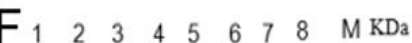

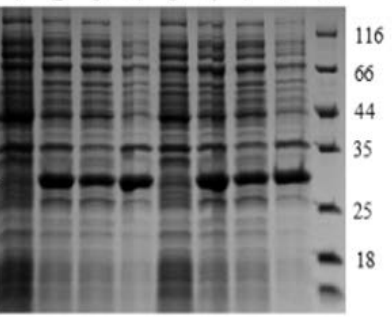

I

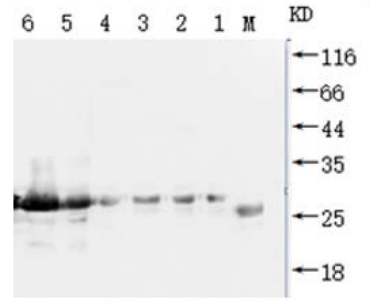

Figure 1. Construct hAMTN gene and express and purify hAMTN protein. (A) Agarose gel electrophoresis (1\%) of the PCR products. M, DM 2000 Marker; 1, PCR products. (B) Double digestion of the pET-28a (+)-AMTN construct. M, Trans2k Plus DNA Marker; 1 , double digestion of pET-28a (+)-AMTN. (C) Agarose gel electrophoresis (1\%) of the colony PCR products showing the BL21 (DE3) clones containing hAMTN gene. M, DM2000 Marker; 1, BL21 (DE3) clones containing hAMTN gene. (D) SDS-PAGE analysis of pET-28a (+)-AMTN-BL21(DE3) after $1 \mathrm{mM} \mathrm{IPTG}$ induction for $4 \mathrm{~h}$ at $37^{\circ} \mathrm{C}$. (E) SDS-PAGE analysis of pET-28a (+)-AMTN-BL21 (DE3) after induction with $0.1 \mathrm{mM}$ IPTG at $16^{\circ} \mathrm{C}$ for $4 \mathrm{~h}$. (F) SDS-PAGE analysis of pET-28a (+)-AMTN-RossetaTM before or after induction with $0.2 \mathrm{mM} \mathrm{IPTG}$ at $25^{\circ} \mathrm{C}$ or $16^{\circ} \mathrm{C}$ for $4 \mathrm{~h}$. M, protein marker; 1 and 5, total protein before IPTG induction; 2 , total protein after IPTG induction at $25^{\circ} \mathrm{C}$; 3 , supernatant after IPTG induction at $25^{\circ} \mathrm{C}$; 4 , protein precipitation after IPTG induction at $25^{\circ} \mathrm{C} ; 6$, total protein after IPTG induction at $16^{\circ} \mathrm{C} ; 7$, supernatant after IPTG induction at $16^{\circ} \mathrm{C} ; 8$, protein precipitation after IPTG induction at $16^{\circ} \mathrm{C}$. (G) SDS-PAGE analysis showing AMTN purification using a Ni-NTA Superflow Cartridge. M, protein marker; 1, total protein after IPTG induction; 2, supernatant after IPTG induction; 3, protein precipitation after IPTG induction; 4, flow-through fraction; 5, wash fraction; 6, pellet; 7 - 10, elution fraction (with elution buffers containing 50, 100, 150, $200 \mathrm{mM}$ of imidazole, respectively). (H) SDS-PAGE analysis showing AMTN purification using an anion-exchange Resource Q packed column. M, protein marker; 1, pre-purification sample; 2, elution fraction. (I) Western blot analysis confirmed that the $28 \mathrm{kDa}$ purified protein was hAMTN protein. M, protein marker; 1 , total protein before IPTG induction; 2, total protein after IPTG induction; 3, supernatant after IPTG induction; 4, protein precipitation after IPTG induction; 5, protein purified with the Ni-NTA Superflow Cartridge; 6, protein further purified with the anion-exchange Resource Q packed column. 


\subsection{Expression Optimization of Recombinant Full-Length hAMTN Protein}

pET-28a (+)-AMTN was transformed into the competent E. coli strain BL21 (DE3) and the clones containing hAMTN gene were selected by colony PCR (Figure 1(C)). A hTMTN expression culture was prepared with BL21 cells containing hAMTN gene. $1 \mathrm{mM}$ IPTG was added after the culture reached $0.6 \mathrm{OD}$ at $600 \mathrm{~nm}$. The culture was then continued for 4 hours at $37^{\circ} \mathrm{C}$. The SDS-PAGE analysis showed an abundant expression of hAMTN protein (the $28 \mathrm{kDa}$ band) in the protein precipitation after sonication. In contrast, the $28 \mathrm{kDa}$ band was weak in the supernatant, indicating that the hAMTN protein was mainly expressed in the form of inclusion bodies (Figure 1(D)). The pET-28a (+)-AMTN-BL21 (DE3) clones were also treated with $0.1 \mathrm{mM}$ or $0.2 \mathrm{mM}$ IPTG at $16^{\circ} \mathrm{C}$ for $4 \mathrm{~h}$. The 28 $\mathrm{kDa}$ band was prominent in the protein precipitation after sonication, while was much weaker in the supernatant, as indicated by the SDS-PAGE analysis (Figure 1(E)). pET-28a (+)-AMTN was also transformed into the competent E.coli strain RossetaTM, and the clones containing the hAMTN gene, pET-28a (+)-AMTN-RossetaTM, was treated with $0.2 \mathrm{mM}$ IPTG at $37^{\circ} \mathrm{C}$ for $4 \mathrm{~h}$. SDS-PAGE analysis revealed obvious $28 \mathrm{kDa}$ bands in both precipitate and supernatant after sonication, indicating that the soluble hAMTN protein expression can be achieved in the RossetaTM strain. The pET-28a (+)-AMTN-RossetaTM clones were also treated with $0.2 \mathrm{mM} \mathrm{IPTG}$ at $25^{\circ} \mathrm{C}$ or $16^{\circ} \mathrm{C}$ for $4 \mathrm{~h}$. Neither of the induction conditions resulted in a higher hAMTN protein expression level in the supernatant than in the protein precipitation after sonication. The highest soluble hAMTN protein expression can be achieved by induction with $0.2 \mathrm{mM}$ IPTG at $16^{\circ} \mathrm{C}$ overnight (Figure $1(\mathrm{~F})$ ).

\subsection{Large-Scale Expression and Purification of Recombinant Full-Length hAMTN Protein}

As indicated by SDS-PAGE analysis, the elution buffer containing $250 \mathrm{mM}$ of imidazole resulted in a $28 \mathrm{kDa}$ band, demonstrating that the AMTN protein was roughly purified (Figure $1(\mathrm{G})$ ). The eluted protein was further purified using an anion-exchange Resource Q packed column. After stringent washing steps, non-specific proteins were significantly removed and a $28 \mathrm{kDa}$ protein with a purity exceeding $90 \%$ was yielded (Figure $1(\mathrm{H})$ ). As confirmed by Western blot analysis, the $28 \mathrm{kDa}$ protein was hAMTN protein with HIS * Tag (Figure 1(I))

\subsection{TEM Analysis Revealed the Self-Assembly Processes of Full-Length Human AMTN Protein}

As indicated by Figure 2(A), 1 min after the reaction solutions of the AMTN protein were prepared, AMTN protein molecules aggregated to form nano-spheres with diameters ranging from $10 \mathrm{~nm}$ to $30 \mathrm{~nm}$ (Figure 2(A) black arrows). Ten minutes after the reaction solutions were prepared, long chain-like structures were detected. The crystals were more densely packed, and the 
"beads" on the chain-like structures were larger (Figures 2(B)-(D)).

\subsection{Topography and Composition of the Crystals Newly Formed on Tooth Slices during Tooth Remineralization}

SEM analysis was firstly performed on tooth slices etched with $30 \%$ phosphoric acid for $60 \mathrm{~s}$. Etched tooth slices were then incubated with AMTN protein solution, followed by treatment with the mineralization solution. SEM analysis demonstrated that AMTN incubation with $1 \mathrm{~d}$ remineralization treatment resulted in sphere-like deposit of calcium phosphate crystals (Figure 3(C)) and dentinal tubules surface (Figure 3(D)). $7 \mathrm{~d}$ treatment in the mineralization solution leaded to a layer of densely packed deposits and spherical projections and recessions can be observed (Figure 3(E)). The dentin surface was also covered with a layer of deposits (Figure 3(F)). The deposits shared similar form and arrange with AM group (Figure $3(\mathrm{G})$, Figure $3(\mathrm{H})$ ). $7 \mathrm{~d}$ treatment in the mineralization solution without AMTN pre-incubation resulted in a layer of densely-packed, sheet-like crystals on the surface of the tooth slices much less organized (Figure 3(I), Figure 3(J)), indicating that the AMTN protein plays an important role in promoting aggregation and organization of newly formed HAP crystals.

The deposits on the tooth slices after AMTN incubation and $7 \mathrm{~d}$ remineralization treatment were subjected to XRD analysis (Figure 4). The $2 \theta$ values for the deposit peaks were perfectly matched the four characteristics peaks of HAP at crystal plans (002), (211), (112), and (300).
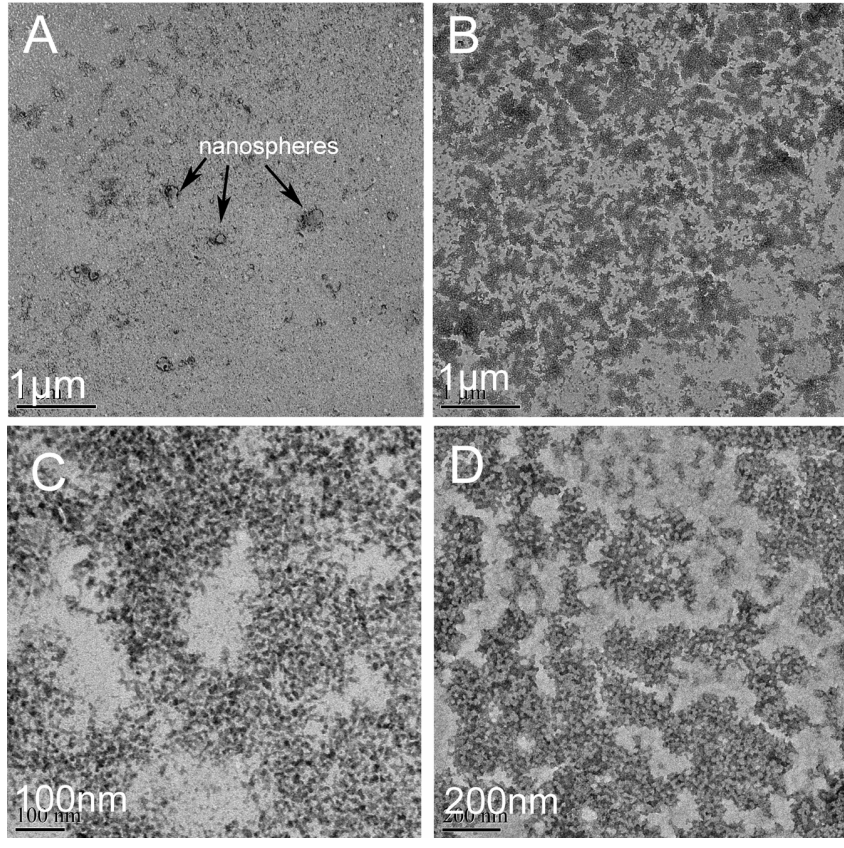

Figure 2. Self-assembly processes of full-length human AMTN protein as indicated by TEM analysis. (A) One minute after the reaction solutions of the AMTN protein were prepared. The black arrows showed the nano-spheres were the basic units in this period; ((B)-(D)) Ten minutes after the reaction solutions of the AMTN protein were prepared. 

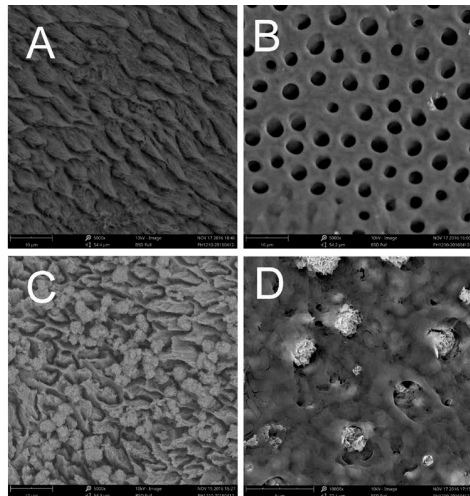

D
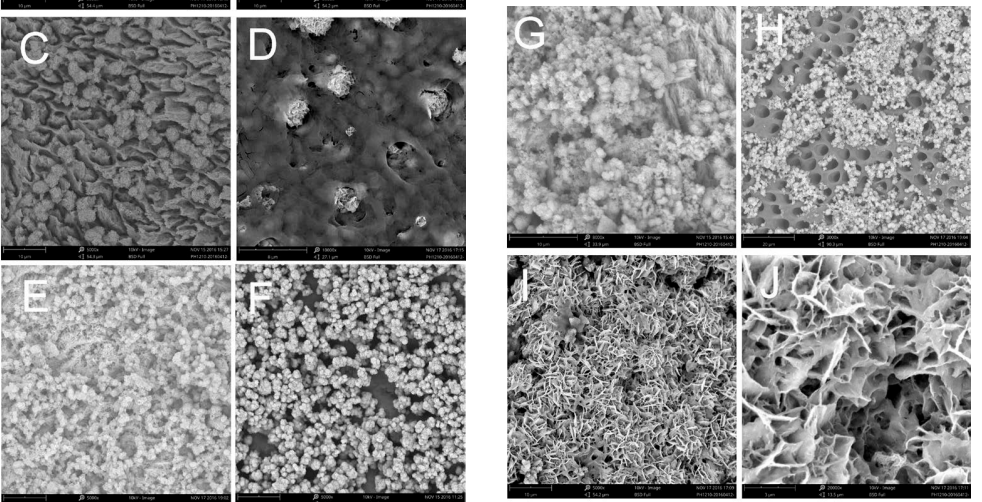

Figure 3. SEM analysis showing the surface topography of the crystals newly formed on tooth slices during tooth remineralization. (A) Demineralized enamel surface. Interrod substance was dissolved (B) Demineralized dentin surface. Contents of dentin tubule were dissolved (C) AMTN incubation with $1 \mathrm{~d}$ remineralization treatment. Deposits filled the blanks of interrod. (D) AMTN incubation with $1 \mathrm{~d}$ remineralization treatment, the deposits sealed the dentinal tubules ((E), (F)) AMTN incubation with $7 \mathrm{~d}$ remineralization treatment. $((\mathrm{G}),(\mathrm{H}))$ AM incubation with $7 \mathrm{~d}$ remineralization treatment. ((I), (J)) Remineralization treatment for $7 \mathrm{~d}$ without AMTN pre-incubation.

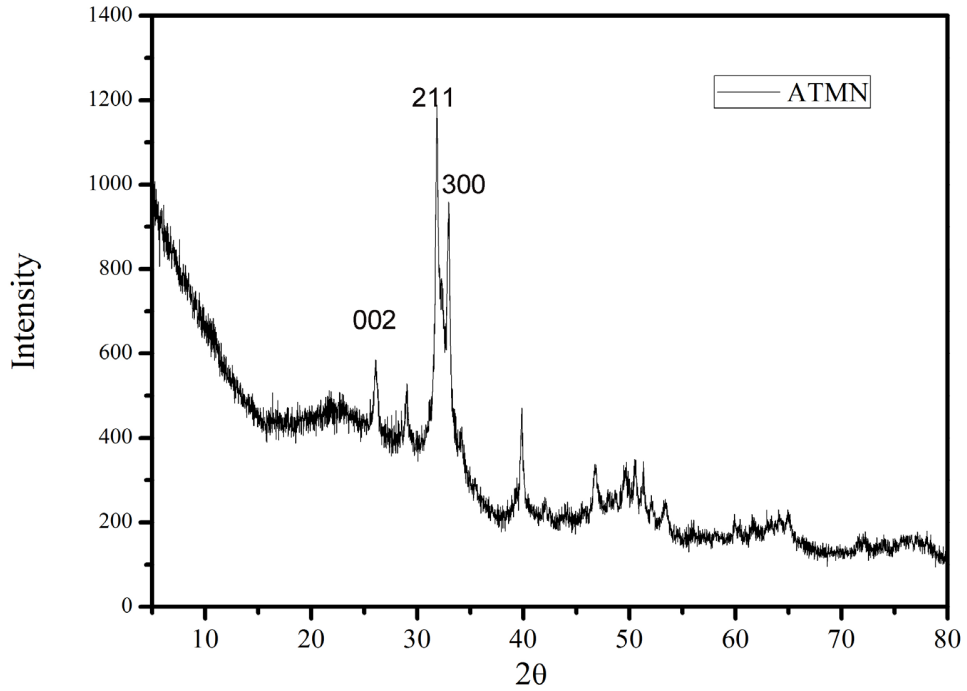

Figure 4. XRD analysis of the deposits on the tooth slices after AMTN incubation and $7 \mathrm{~d}$ of remineralization treatment.

\section{Discussion}

To achieve a stable expression of hAMTN protein, we found that the highest soluble hAMTN protein expression can be achieved by induction with $0.2 \mathrm{mM}$ IPTG at $16^{\circ} \mathrm{C}$ overnight which was used for the large-scale expression of hAMTN protein and necessary for the following protein self-assembly and bio- 
mineralization experiments. After the two-step purification, a $28 \mathrm{kDa}$ protein with a purity exceeding $90 \%$ was yielded. To observe the self-assembly processes of hAMTN protein, reaction solutions of the AMTN protein $(100 \mu \mathrm{g} / \mathrm{mL}, \mathrm{pH}=$ 7.6) were prepared on ice by diluting the AMTN stock solutions with $50 \mathrm{mM}$ Tris- $\mathrm{HCl}(\mathrm{pH}=7.6)$. Prolonged self-assembly time leads to larger nanoparticles with increased diameters, with structures more similar to that of an enamel prism. As indicated by SEM analysis, self-assembled hAMTN protein. In summary, this study showed that AMTN under right condition undergoes a self-assembly process that produces nano-particulate structure units and higher-order fabric-like structure.

\section{Acknowledgements}

We thank all the subjects for their participation. This work was supported by Applied Basic Research Programs of Science and Technology Commission Foundation of Sichuan Province, China (2018JY0057 to K.T); Oral Transplantation Project Sichuan Youth Science and Technology Innovation Research Team (2021JDTD0005 to K.T).

\section{Conflicts of Interest}

The authors declare no conflicts of interest regarding the publication of this paper.

\section{References}

[1] Chun, K., Choi, H. and Lee, J. (2014) Comparison of Mechanical Property and Role between Enamel and Dentin in the Human Teeth. Journal of Dental Biomechanics, 5. https://doi.org/10.1177/1758736014520809

[2] Chen, H., Clarkson, B.H., Sun, K. and Mansfield, J.F. (2005) Self-Assembly of Synthetic Hydroxyapatite Nanorods into an Enamel Prism-Like Structure. Journal of Colloid and Interface Science, 288, 97-103. https://doi.org/10.1016/j.jcis.2005.02.064

[3] Koto, W., Shinohara, Y., Kitamura, K., Wachi, T., Makihira, S. and Koyano, K. (2017) Porcine Dental Epithelial Cells Differentiated in a Cell Sheet Constructed by Magnetic Nanotechnology. Nanomaterials (Basel, Switzerland), 7, 322. https://doi.org/10.3390/nano7100322

[4] Yamazaki, H., Beniash, E., Yamakoshi, Y., Simmer, J.P. and Margolis, H.C. (2017) Protein Phosphorylation and Mineral Binding Affect the Secondary Structure of the Leucine-Rich Amelogenin Peptide. Frontiers in Physiology, 8, 450. https://doi.org/10.3389/fphys.2017.00450

[5] Margolis, H.C., Kwak, S.Y. and Yamazaki, H. (2014) Role of Mineralization Inhibitors in the Regulation of Hard Tissue Biomineralization: Relevance to Initial Enamel Formation and Maturation. Frontiers in Physiology, 5, 339. https://doi.org/10.3389/fphys.2014.00339

[6] Gibson, C.W., Yuan, Z.A., Hall, B., Longenecker, G., Chen, E., Thyagarajan, T., Sreenath, T., Wright, J.T., Decker, S., Piddington, R., Harrison, G. and Kulkarni, A.B. (2001) Amelogenin-Deficient Mice Display an Amelogenesis Imperfecta Phenotype. The Journal of Biological Chemistry, 276, 31871-31875.

https://doi.org/10.1074/jbc.M104624200 
[7] Hu, J.C., Hu, Y., Smith, C.E., McKee, M.D., Wright, J.T., Yamakoshi, Y., Papagerakis, P., Hunter, G.K., Feng, J.Q., Yamakoshi, F. and Simmer, J.P. (2008) Enamel Defects and Ameloblast-Specific Expression in Enam Knock-Out/Lacz Knock-In Mice. The Journal of Biological Chemistry, 283, 10858-10871. https://doi.org/10.1074/jbc.M710565200

[8] Wazen, R.M., Moffatt, P., Zalzal, S.F., Yamada, Y. and Nanci, A. (2009) A Mouse Model Expressing a Truncated Form of Ameloblastin Exhibits Dental and Junctional Epithelium Defects. Matrix Biology: Journal of the International Society for Matrix Biology, 28, 292-303. https://doi.org/10.1016/j.matbio.2009.04.004 